\title{
Revista Sergipana de Educação Ambiental \begin{tabular}{l|l|l} 
& \\
.4 & $N^{0} 4$ & 2017
\end{tabular}
}




\section{UNIVERSIDADE FEDERAL DE SERGIPE}

Prof. Dr. Angelo Roberto Antoniolli

REITOR

Profa. lara Campelo

VICE-REITORA

\section{CONSELHO EDITORIAL}

Aneide Oliveira Araújo (Universidade Federal do Rio Grande do Norte)

Alexandre Pedrine (Universidade Federal do Rio de Janeiro)

Alice Alexandre Pagã (Universidade Federal de Sergipe)

Aline Lima de Oliveira Nepomuceno (Universidade Federal de Sergipe)

Ana Catarina Lima de Oliveira Machado (Instituto Federal de Sergipe)

Angelo Pitanga (Instituto Federal da Bahia)

Cae Rodrigues (Universidade Federal de Sergipe)

Carmen Regina Parisoto (Universidade Federal de Sergipe)

Daniela Bitencourt (Universidade Federal de Sergipe)

Edileuza Dias Queiroz (Universidade Federal Rural do Rio de Janeiro)

Glebson Moura (Universidade Federal de Sergipe)

Helen Barbosa Raiz Engler (Universidade Estadual Paulista)

Marco Antônio Leandro Barzano (Universidade Estadual de Feira de Santana)

Maria da Conceição Pereira Ramos (Universidade do Porto)

Maria José Nascimento Soares (Universidade Federal de Sergipe)

Marlécio Naknamara da Silva Cunha (Universidade Federal da Bahia)

Mônica Lopes Folena de Araújo (Universidade Federal de Pernambuco)

Natália Ramos (Universidade Aberta)

Olívio Godinho Patrício (Universidade de Lisboa)

Paulo Heimar Souto (Universidade Federal de Sergipe)

Patrícia Domingos (Universidade Federal do Rio de Janeiro)

\section{CAPA, PROJETO GRÁFICO E EDITORAÇÃO ELETRÔNICA}

Tatiana Ferreira dos Santos 


\title{
Revista Sergipana de
}

\section{Educação Ambiental}

\begin{abstract}
A Revista Sergipana de Educação Ambiental (ReviSea) é uma publicação semestral, do Grupo de Estudo e Pesquisa em Educação Ambiental de Sergipe (GEPEASE) e do Projeto Sala Verde na UFS, tem como objetivo disseminar resultados e reflexões advindos de investigações científicas e vivências metodológicas desenvolvidas no campo da Educação Ambiental em Sergipe, que possam contribuir para a consolidação desta abordagem de educação em ambientes formais e não formais de aprendizagem, para a formação de professores e para a produção de conhecimentos em Educação Ambiental, que fundamentem o desenvolvimento de práticas educativas participativas e comprometidas com os princípios da Educação Ambiental, com o desenvolvimento de valores éticos, de pertença, de respeito e coletividade a fim de vislumbrar o bem estar da comunidade.

Dedica-se à publicação de artigos acadêmico-científicos, resenhas, conferências e comunicações, fomentando e facilitando o intercâmbio acadêmico no âmbito nacional e internacional.

É dirigida a professores e pesquisadores dos diferentes níveis, principalmente da educação básica, assim como a estudantes da graduação e pós-graduação de todas as áreas de conhecimento.
\end{abstract}




\section{EQUIPE EDITORIAL}

Profa. Dra. Maria Inêz Oliveira Araújo

Profa. Dra. Daniela Venceslau Bitencourt

Profa. Ma. Maria Ivanilde Meneses de Oliveira

Profa. Ma. Mônica Andrade Modesto

Profa. Ma. Nádia Batista de Jesus

Profa. Dra. Sindiany Suelen Caduda dos Santos

Profa. Ma. Tatiana Ferreira dos Santos

Profa. Me. Tiago Rozário da Silva

\section{Endereço postal:}

Av. Mal. Rondon, s/nº, Jardim Rosa Elze, São Cristóvão - SE, 49100-000. Pró- Reitoria de Extensão e Assuntos Comunitários (PROEX). Projeto Sala Verde na UFS.

\section{Contato Principal}

Maria Inêz Oliveira Araujo

Dra. em Educação

Universidade Federal de Sergipe

Telefone: [79] 21056422

E-mail: inez@ufs.br

\section{Contato para Suporte Técnico}

Tatiana Ferreira dos Santos

Telefone: [79] 2105-6422

Email: suporterevisea@yahoo.com.br

Ficha catalográfica elaborada pela biblioteca central Universidade Federal de Sergipe

Revista Sergipana de Educação Ambiental : REVISEA / Grupo de Estudo e Pesquisa do Estado de Sergipe (GEPEASE) ; Projeto Sala Verde na UFS. - Vol. 1, n.2 (2014)- . - São Cristóvão : Universidade Federal de Sergipe, 2014- Semestral ISSN 2359-4993

1. Educação ambiental - Sergipe. I. Grupo de Estudo e Pesquisa do Estado de Sergipe (GEPEASE). II. Projeto Sala Verde na UFS. 


\section{Editorial}

Revista Sergipana de Educação Ambiental traz na edição de 2017, as pes-
quisas científicas que se destacaram no Curso de Especialização em Educa-
ção Ambiental, da Universidade Federal de Sergipe.

Esta edição amplia discussões teórico-práticas no tocante a Educação Ambiental no espaço formal, iniciadas na edição de 2016. Nesse sentido, estendemos a discussão acerca de pesquisas teórico-práticas que mostram a relevância da Educação Ambiental na Educação Básica.

Isto posto, convido a todos/as leitores/as a mergulhar na leitura de trabalhos científicos que revelam desafios e potencialidades de uma Educação Ambiental crítica. Convido-os ainda a inspirar-se nas histórias de sujeitos ecológicos (professores/as da rede de ensino básico de Sergipe e participantes das pesquisas) que retratam de maneira científica como é possível trabalhar em favor de Educação Ambiental transformadora. 


\section{Apresentação}

Prezado leitor, a edição de 2017 da Revista Sergipana de Educação Ambiental é composta por artigos científicos referentes à temática Educação Ambiental Formal, organizada pela professora Dra. Maria Inêz Oliveira Araujo, da Universidade Federal de Sergipe, juntamente com os membros da equipe editorial do periódico.

Esta edição é constituída por oito artigos que versam sobre ações de Educação Ambiental ocorridas no âmbito formal de ensino. A base teórica desenvolvida compreende a EA como uma práxis contínua, permanente e interdisciplinar que deve permear todos os níveis e modalidades de ensino.

Destarte, o primeiro artigo, intitulado "A Abordagem da Educação Ambiental na sala de aula da EMEF Sérgio Francisco da Silva" verificou como se dá a abordagem da EA a partir da análise do Projeto Político Pedagógico (PPP) da Escola, bem como se os professores desta unidade de ensino abordam a EA com os discentes, e qual o conceito destes em relação ao tema. Na sequência, o artigo "Análise da implantação e atuação da COM-VIDA na Escola Municipal Genesio Chagas", sustentado na Educação Ambiental Crítica, analisou a implantação e atuação da Com-Vida na Escola Municipal Genésio Chagas, localizada no povoado Cumbe II, na cidade de Simão Dias-SE, refletindo, sobre possibilidades e limites do desenvolvimento da proposta. O terceiro artigo, denominado "Análise Socioambiental das Condições Hídricas da Escola Municipal Telma de Souza Almeida em Tobias Barreto", investigou a percepção da comunidade escolar sobre as condições de consumo de água fornecida, face aos sérios problemas socioambientais enfrentados na distribuição dos recursos hídricos da cidade de Tobias Barreto, Sergipe. Em continuidade, o trabalho científico "Concepções de Educação Ambiental e Interdisciplinaridade dos docentes do Colégio Estadual Benedito Barreto do Nascimento", analisou as diferentes concepções de Educação Ambiental e interdisciplinaridade, a fim de compreender como os/as docentes inserem educação ambiental nas práticas pedagógicas. Em seguida, o quinto artigo intitulado "Águas de pertencimento: um estudo sobre percepção e prática de Educação Ambiental", analisou a percepção que os alunos têm em relação ao problema da poluição dos rios e da constante falta de água no município de São Cristóvão. Já o texto "Possibilidades para a promoção da Educação Ambiental através da problematização sobre resíduos sólidos na Escola", objetivou reconhecer a importância da promoção da Educação Ambiental a partir da problematização sobre resíduos sólidos na escola, compreendendo que a base teórica apreendida nas disciplinas não pode estar dissociada da vivência em sociedade e da formação integral do cidadão. O sétimo artigo denominado "Práticas de Educação Ambiental no Ensino Infantil: o trabalho da Escola Profa Áurea Melo Zamor em Aracaju-SE", analisou como vem sendo trabalhada a educação ambiental no ensino infantil, para que as crianças adquiram conhecimentos, desenvolvam habilidades, e se tornem conscientes e sensíveis no que se refere ao meio ambiente. O último artigo, intitulado "A educação ambiental 
no Colégio Estadual Armindo Guaraná, São Cristóvão/SE", u identificar as formas de abordagens da Educação Ambiental (EA) na prática pedagógica de docentes do Colégio Estadual Armindo Guaraná, na cidade de São Cristóvão/SE, em turmas do Ensino Fundamental.

Cabe sinalizar que estes artigos passaram por um sistema de avaliação por pares e às cegas. Ademais, as ideias expressas em cada um deles é de exclusiva responsabilidade dos/as autores/as.

Nesse sentido, esperamos que os saberes e práticas desvelados por cada artigo alentem reflexões, estimulem a formação de novos/as educadores ambientais, incentivem novos trabalhos na Educação Básica com enfoque na Educação Ambiental Crítica e fortaleçam as ações socioambientais de modo coletivo.

Ao/a leitor/a, fica ainda o convite da equipe editorial para que contribua conosco de forma científica e permita que novas experiências teórico-práticas no cenário da Educação Ambiental brasileira sejam compartilhadas. 


\section{Sumário}

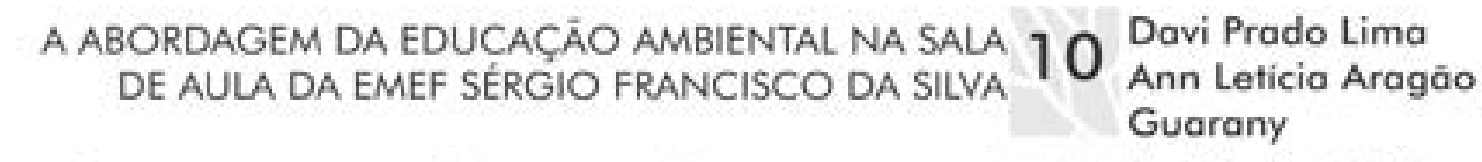

ANÁLISE DA IMPLANTAÇĀO E ATUAÇÃO DA COM-VIDA NA ESCOLA MUNICIPAL GENÉSIO CHAGAS

24 Andréa Santa Rosa do Rosário

Mônica Andrade Modesto

ANÁLISE SOCIOAMBIENTAL DAS CONDIÇŌES 37 Jeane Cruz Andrade Silva HIDRICAS DA ESCOLA MUNICIPAL TELMA DE SOUZA 37 Roseli Pereira Nunes

ALMEIDA EM TOBIAS BARRETO Bastos

\section{CONCEPÇŌES DE EDUCAÇĀO AMBIENTAL E 50 Pedro Ernesto Oliveira da INTERDISCIPLINARIDADE DOS DOCENTES DO 50 Cruz COLÉGIO ESTADUAL BENEDITO BARRETO DO Rodrigo Bozi Ferrete NASCIMENTO}

ÁGUAS DE PERTENCIMENTO: UM ESTUDO SOBRE PERCEPÇĀO E PRÁTICA DE EDUCAÇĀO AMBIENTAL

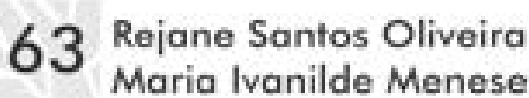

POSSIBILIDADES PARA A PROMOÇĀO DA EDUCAÇÃO AMBIENTAL ATRAVÉS DA PROBLEMATIZAÇẢO SOBRE RESÍDUOS SÓLIDOS NA ESCOLA

77 Orlane Santana Coelho Mônica Andrade Modesto

PRÁTICAS DE EDUCAÇĀO AMBIENTAL NO ENSINO INFANTIL: O TRABALHO DA ESCOLA PROF" ÁUREA MELO ZAMOR EM ARACAJU-SE

A EDUCAÇÃO AMBIENTAL NO COLÉGIO ESTADUAL ARMINDO GUARANÁ, SÃO CRISTÓVĀO/SE
87 Verusia Maruiza de Souza Macedo Firmino Alana Danielly Vasconcelos Aline Lima de Oliveira Nepomuceno
96 Adeilton dos Santos 